NASA Technical Memorandum 87039

\title{
Low-Speed Aerodynamic Test of an Axisymmetric Supersonic Inlet with Variable Cowl Slot
}

\author{
A.G. Powell and H.R. Welge \\ Douglas Aircraft Company \\ Long Beach, California \\ and \\ C.J. Trefny \\ Lewis Research Center \\ Cleveland, Ohio
}

Prepared for the

Twenty-first Joint Propulsion Conference cosponsored by the AIAA, SAE, and ASME Monterey, California, July 8-10, 1985 


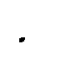

. 


\title{
LOW-SPEED AERODYNAMIC TEST OF AN AXISYMMETRIC SUPERSONIC INLET WITH VARIABLE COWL SLOT*
}

\author{
A. G. Powell and H. R. Welge, Douglas Aircraft Co. \\ C. J. Trefny, NASA Lewis Research Center
}

\begin{abstract}
The experimental low-speed aerodynamic characteristics of an axisymmetric mixed-compression supersonic inlet with variable cowl slot are described. The model consisted of the NASA P-inlet centerbody and redesigned cowl with variable cowl slot powered by the JT8D single-stage fan simulator and driven by an air turbine. The model was tested in the NASA Lewis Research Center 9- by 15 -foot low-speed tunnel at Mach numbers of $0,0.1$, and 0.2 over a range of flows, cowl slot openings, centerbody positions, and angles of attack. The variable cowl slot was effective in minimizing lip separation at high velocity ratios, showed good steady-state and dynamic distortion characteristics, and had good angle-of-attack tolerance.
\end{abstract}

\section{NOMENCLATURE}

\section{Stations}

0

1

2

Variables

A

$\Gamma$

$\mathbf{M}$

$\mathbf{P}_{\mathrm{T}}$

$\mathbf{P}_{\mathrm{T} 2}$

R

$\mathbf{R}_{\text {LIP }}, R_{L}$

Area

Corrected weightflow, $\mathrm{W} \sqrt{ } \theta / \delta$

Mach number

Total pressure

Steady-state area averaged total pressure at diffuser exit

Radius from inlet centerline

$\mathbf{R}_{\text {CowL }}, \mathbf{R}_{C} \quad$ Cowl inside radius at the measurement station

$\mathbf{R}_{\mathrm{HUB}}, \mathbf{R}_{\mathrm{TIP}}$ Radii describing annular flow area at diffuser exit

$\mathrm{X}_{\mathrm{CB}} \quad$ Centerbody translation measured forward from the fully retracted position

$\mathrm{X}_{\mathrm{SLOT}}, \mathrm{X}_{\mathrm{S}} \quad$ Slot opening or forward cowl translation

\section{INTRODUCTION}

The supersonic cruising efficiency of the axisymmetric mixed-compression inlet is unmatched in terms of high total pressure recovery and low installation drag. However, under conditions typical of takeoff and initial climb, i.e., high weightflow and low freestream Mach, the sharp cowl lip required for supersonic efficiency suffers flow separation, resulting in poor total pressure recovery and high distortion. While lip separation can be alleviated to some degree by retracting the centerbody, thus increasing lip-to-throat-area ratio and reducing lip Mach number, the cowl internal contraction necessary for supersonic operation reduces inlet throat area which results in supercritical flow and shock losses.

One way to meet engine airflow demand while maintaining reasonable inlet recovery is through the use of blow-in doors. This approach has been used successfully (Reference 1). An alternate approach is to open up a carefully shaped cowl slot by translating the front part of the cowl forward, as shown in Figure 1. In principle, such a device might have lower distortion than the blow-in door due to its axisymmetric nature and remote placement relative to the compressor face. A previous test of a variable cowl slot in a subsonic inlet is described in Reference 2.

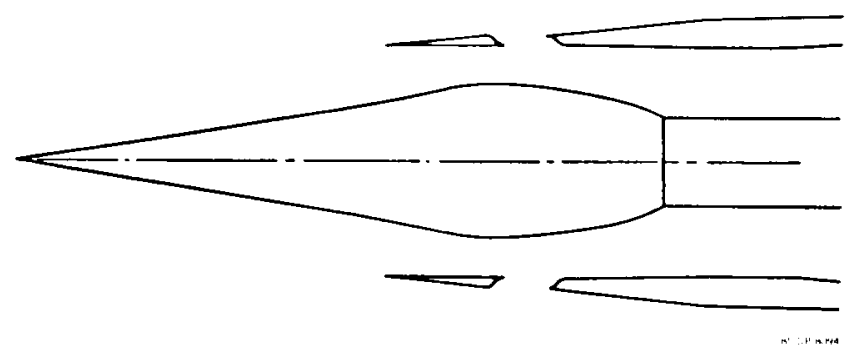

FIGURE 1. VARIABLE COWL SLOT

Douglas Aircraft Co., along with Lockheed and Boeing, participated in an experimental program with NASA Lewis to evaluate various auxiliary airflow concepts at low speed on a supersonic mixedcompression inlet. The activity was part of the Supersonic Cruise Research program administered at NASA Langley. The NASA Ames P-inlet model, designed for a cruise Mach of 2.65 and tested extensively at Ames under supersonic conditions, was chosen as the basis for testing. The NASA Lewis-Pratt \& Whitney JT8D single-stage refan model, driven by an air turbine, was used to induce airflow into the inlet. The NASA Lewis 9 - by 15 -foot low-speed anechoic tunnel was used for the tests. The tests were concerned with both aerodynamic and acoustic performance, from 0 to 0.2 Mach and from 0

"Reprint of Douglas Paper 7551 prepared for the Twenty-first Joint Propulsion Conference cosponsored by the AIAA, SAE, and ASME, 1 Monterey, California, July 8-10, 1985. 
to 20 degrees angle of attack. NASA Lewis, Lockheed, and Boeing tested blow-in door-type devices; Douglas tested a variable cowl slot. This paper discusses the aerodynamic performance part of the Douglas test.

The objectives of the aerodynamic performance test were to:

1. Determine the effectiveness of the variable cowl slot under simulated takeoff conditions

2. Find the best combination of cowl slot opening and centerbody position

3. Determine the effects of angle of attack.

Initially, the aerodynamic implications of the various geometric variables associated with the inlet were unknown. The radial distance from the slot to the centerbody, which varies with centerbody position, could affect the degree of flow separation at the sharp slot lip, as could the proximity of the two slot faces to each other. Would the increased slot airflow possible with a wide slot opening offset the increased slot flow separation due to the wider spacing between the two slot faces?

The lip-to-throat area ratio varies with centerbody position. Cowl lip Mach number is decreased by retracting the centerbody, which should decrease lip loss, but the cowl internal contraction typical of this type of inlet causes the throat area to decrease, resulting in supercritical flow and shock losses at the higher massflows. This problem is worsened considerably if retracting the centerbody also places the throat aft of the cowl slot.

In order to allow maximum flexibility in exploring these parameters, the model cowl was designed with very little internal area contraction. This allowed minimum flow area to be placed either ahead of or behind the cowl slot. The inlet was sized to allow choking of the throat at any centerbody position.

\section{APPARATUS AND PROCEDURE}

The total pressure instrumentation for the aerodynamic performance test consisted of Pitot rakes located inside and just aft of the cowl lip, in the inlet throat just downstream of the slot, and at the diffuser exit. Two rows of static pressure taps lined both the centerbody and the cowl interior. The pressure data were processed by on-site computing equipment, allowing real-time monitoring of important parameters.

A schematic of the Lewis 9- by 15-foot facility is shown in Figure 2 The facility is unique in that the 9 by 15 low-speed test section is part of the return loop for the 8- by 6-foot supersonic tunnel.

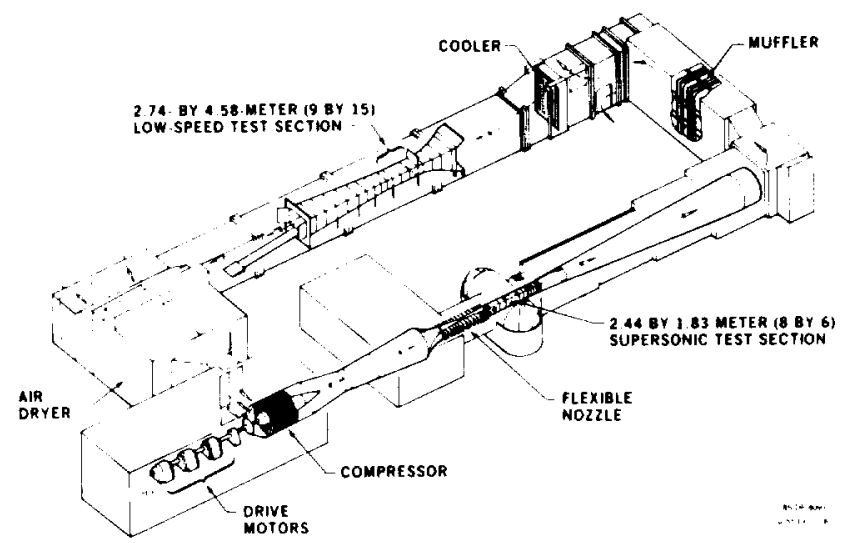

FIGURE 2. B. BY 6-FOOT AND 9- BY 15-FOOT WIND TUNNELS
The model installation is shown in Figure 3. The inlet model, fan, and air turbine are mounted as a unit to a rotatable column mount offset from the tunnel centerline to allow the inlet to be tested over a wide angular range without significant wall effect. The centerbody axial position and inlet angle of attack, as well as fan speed and airflow, were adjustable during tunnel operation. Cowl slot opening had to be adjusted with the tunnel stopped, as this involved readjusting the pressure tube routings. The effect of centerbody and cowl bleed on low-speed inlet performance was not assessed; the bleed holes were sealed for the duration of the test. For a discussion of the effect of bleed on low-speed inlet performance, see Reference 1.

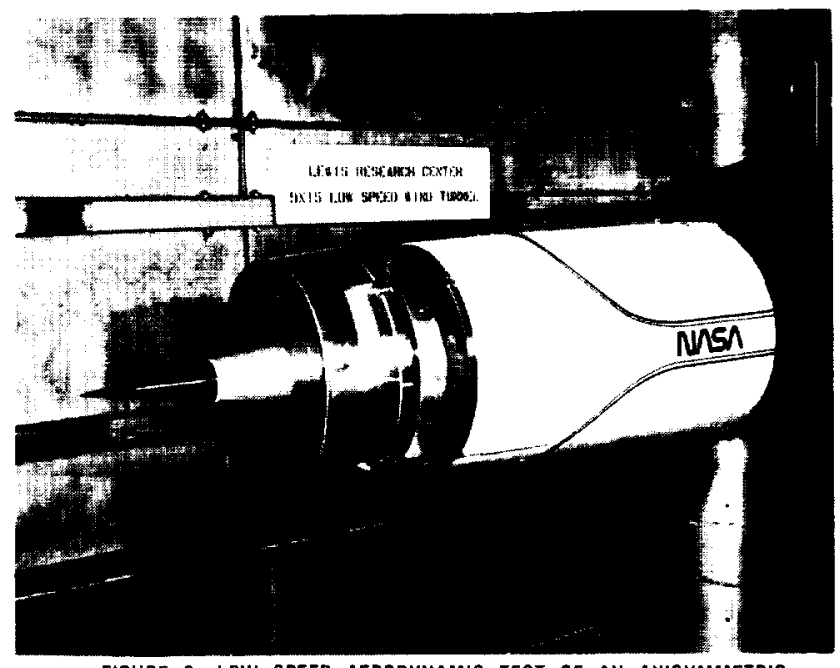

FIGURE 3. LOW SPEED AERODYNAMIC TEST OF AN AXISYMMETRIC SUPERSONIC INLET WITH VARIABLE COWL SLOT.

\section{RESULTS AND DISCUSSION}

\section{PERFORMANCE}

The influence of centerbody location on lip separation with the cowl slot closed and at a freestream Mach of $\mathrm{M}_{0}=0$ is shown in Figure 4. The total-pressure profiles were measured by a Pitot rake located just inside the cowl lip. Retracting the centerbody lowers the lip Mach, although the velocity ratio, $V_{1} / V_{0}$, is infinite for all cases. The increase in the radial extent of separation as the centerbody is retracted is probably a result of the increasing radial distance between the lip and centerbody.

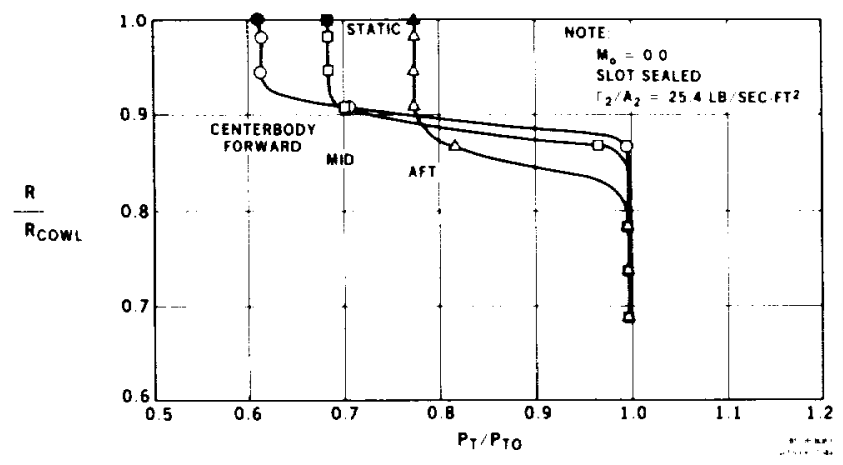

FIGURE 4. EFFECT OF CENTERBODY POSITION ON COWL LIP SEPARATION, $M_{0}=0.0$

The same information is shown in Figure 5, but at a freestream Mach of 0.2 . The radial extent of separation is reduced over the $M_{0}=0$ case due to much decreased velocity ratios. Retracting the centerbody decreases the velocity ratio and reduces the lip Mach. This results in reduced radial extent of separation, and considerably reduced total pressure loss. 


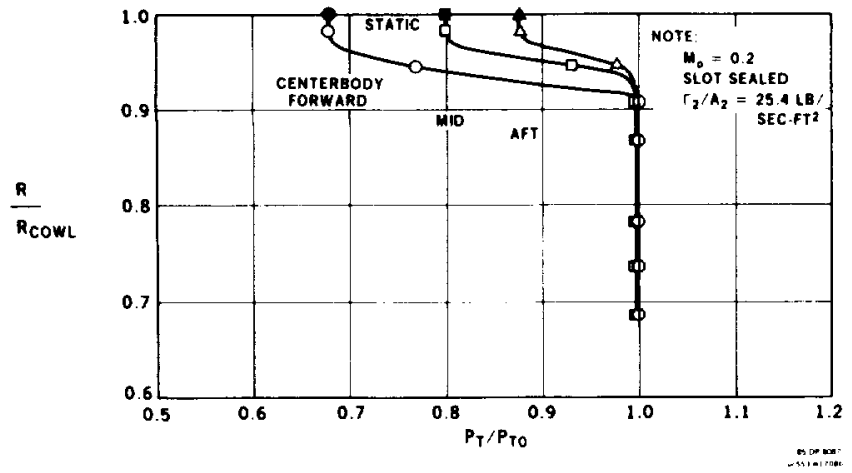

FIGURE 5. EFFECT OF CENTERBOOY POSITION ON COWL LIP SEPARATION, $M_{0}=0.2$

The effect of opening the cowl slot on lip separation is shown in Figure 6. For both freestream Mach numbers, the effect ive lip velocity ratio is markedly reduced by opening the cowl slot. At a Mach of 0.2 , opening the slot essentially eliminates lip separation.

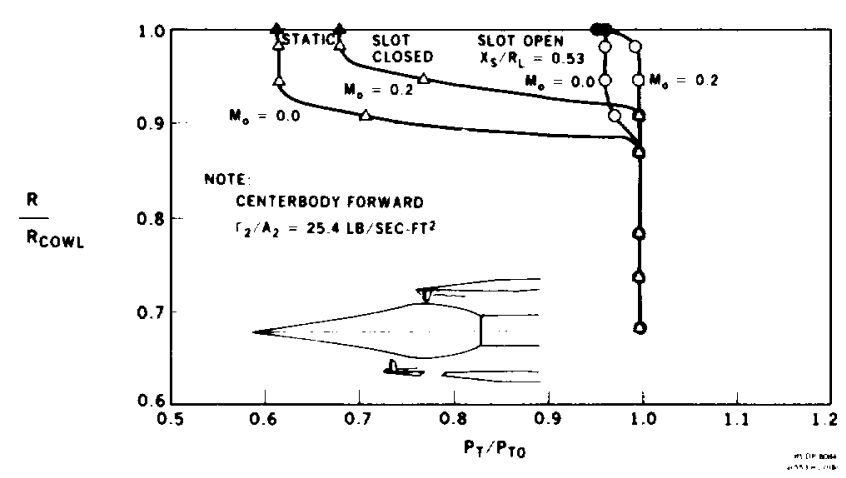

FIGURE 6. EFFECT OF COWL SLOT ON LIP SEPARATION

With the slot open, the best recovery and lowest distortion (not shown) are achieved with the centerbody fully forward at high massflows, as shown in Figure 7. This places the slot aft of the centerbody maximum radius station, providing relief from the supercritical shock losses by virtue of increased effective throat area. Figure 8 shows the total pressure recovery at a freestream Mach of 0.2 , with the centerbody fully forward and the cowl slot fully open $\left(\mathrm{X}_{\mathrm{SLOT}} / \mathrm{R}_{\mathrm{LIP}}=\mathrm{X}_{\mathrm{S}} / \mathrm{R}_{\mathrm{L}}=0.53\right)$. This configuration gave the best overall performance. Included in the figure for comparison is the recovery characteristic with the slot closed and sealed. Recovery for the same configurations at a freestream Mach of 0.0 is shown in Figure 9.

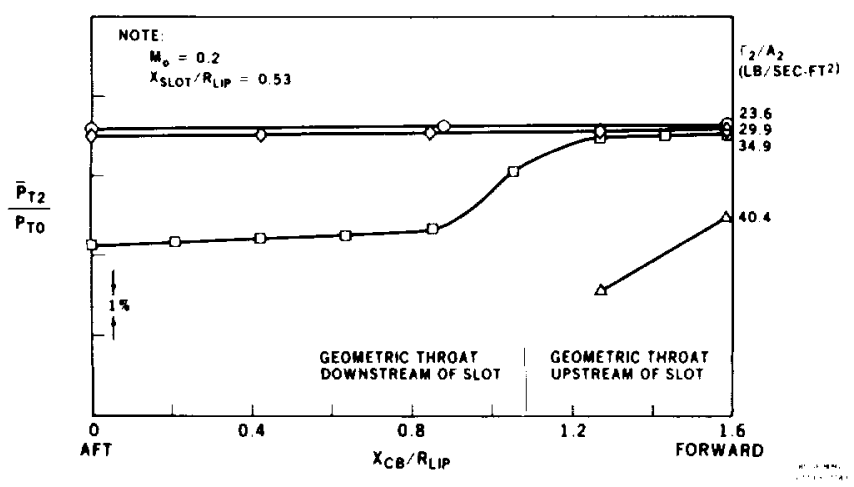

FIGURE 7. EFFECT OF GEOMETRIC THROAT POSITION ON RECOVERY

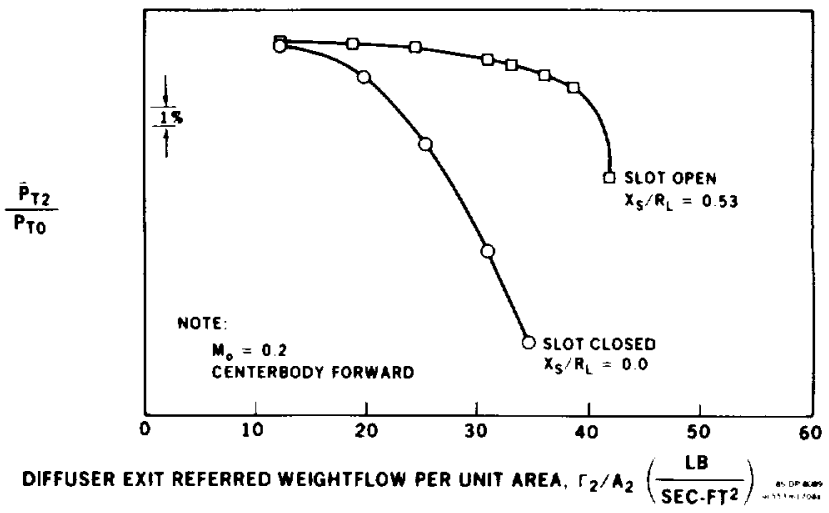

FIGURE 8. TOTAL PRESSURE RECOVERY, $M_{0}=0.2$

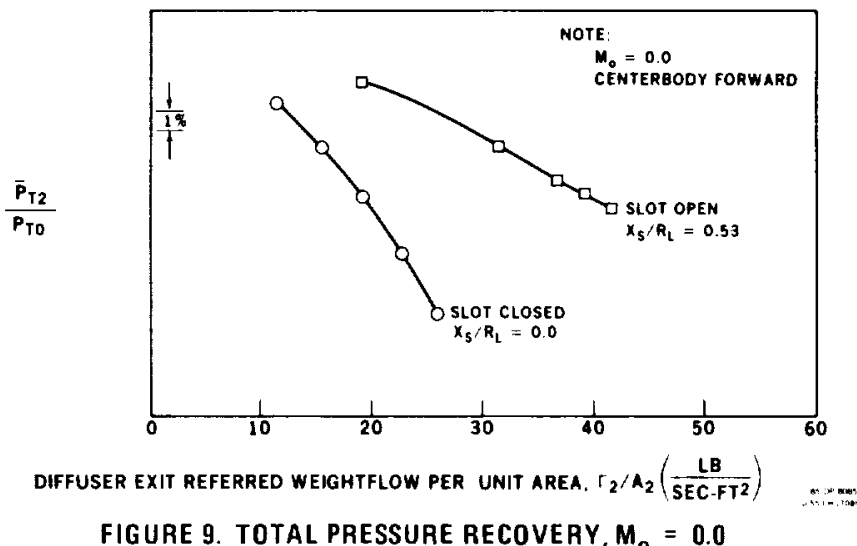

\section{ANGLE OF ATTACK}

The inlet was tested at angles of attack up to 20 degrees with the $\mathrm{X}_{\mathrm{S}} / \mathrm{R}_{\mathrm{L}}=0.53$ slot opening, and to 15 degrees with the other slot openings tested. The variations of total pressure recovery and steadystate distortion with angle of attack are shown in Figure 10 for a diffuser-exit-corrected weight flow per unit area of $31.0 \mathrm{lb} / \mathrm{sec}^{-\mathrm{ft}^{2} \text { and }}$ a tunnel Mach of 0.2. For comparison, the cowl-slot-open $\left(\mathrm{X}_{\mathrm{S}} / \mathrm{R}_{\mathrm{L}}=\right.$ $0.53)$ and closed $\left(X_{S} / R_{L}=0.0\right)$ cases are shown. For both cases, the variation of recovery with angle of attack is small, but the slot-open case shows much less variation in steady-state distortion. The RMS dynamic distortion is not shown, but follows the same trend. At an angle of attack of 20 degrees, steady-state distortion remains below 10 percent and rms dynamic distortion below 2 percent up to a diffuser-exit-corrected weightflow per unit area of $35.9 \mathrm{lb} / \mathrm{sec}-\mathrm{ft}^{2}$ (compressor face Mach $=0.48$ ). Figure 11 shows the effect of opening the cowl slot on compressor face total pressure profiles at an angle of attack of 15 degrees. The influence of the slot is readily apparent.

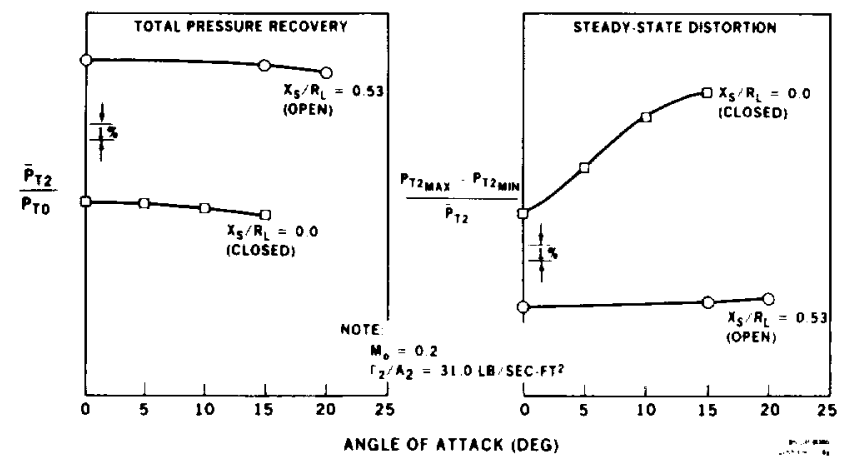

FIGURE 10. EFFECT OF ANGLE OF ATTACK 


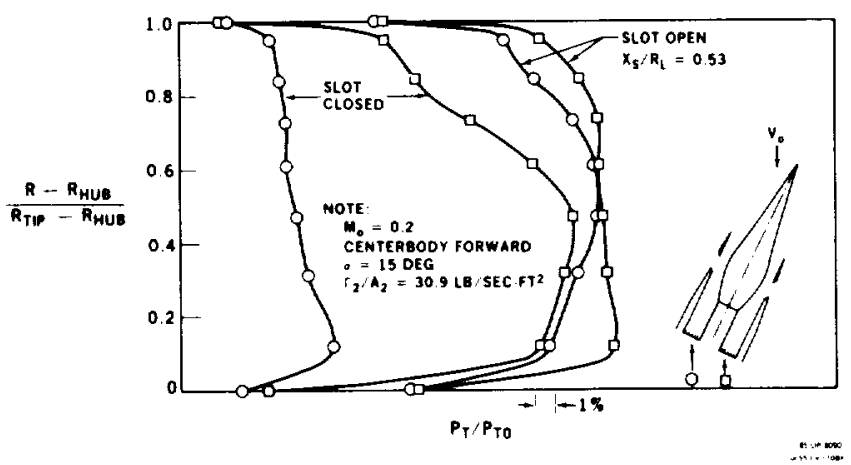

FIGURE 11. DIFFUSER EXIT TOTAL PRESSURE PROFILES

\section{APPLICATION OF DATA TO INLET OPERATION}

The recovery characteristic as a function of freestream Mach for $\mathrm{X}_{\mathrm{S}} / \mathrm{R}_{\mathrm{L}}=0.53$ is shown in Figure 12. The largest improvement in recovery occurs between $M_{0}=0$ and 0.1 . Since relatively little runway is used up at the lower speeds, the lowered performance at $\mathrm{M}_{0}=0$ relative to $\mathrm{M}_{0}=0.1$ or 0.2 is not seen as a serious problem.

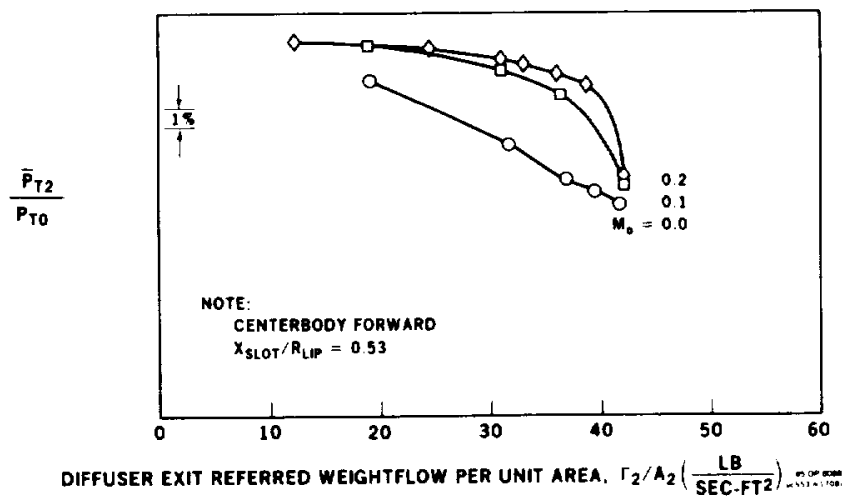

FIGURE 12. RECOVERY IMPROVEMENT WITH FREESTREAM MACH

\section{CONCLUSIONS}

The test and hardware described in this paper were designed to explore the potential of the variable cowl slot as applied to a supersonic inlet, and to quantify its performance as a function of various geometric and flow parameters. The information can then be used to guide the application of the concept to the design of flight hardware. The following conclusions are drawn:

1. The variable cowl slot is effective in reducing sharp-lip separation at low speeds.

2. The best performance is obtained with the cowl slot aft of the inlet throat.

3. The best overall performance was achieved with a slot-openingto-cowl-lip-radius ratio of 0.53 . Larger slot openings should be explored.

\section{REFERENCES}

1. Wasserbauer, J. F., Cubbison, R. W., and Trefny, C. J., "Low Speed Performance of a Supersonic Axisymmetric Mixed Compression Inlet with Auxiliary Inlets," NASA TM 83435, June 1983.

2. Henne, P. A., "Low-Speed Test of Translating Lip Axisymmetric Inlets for Subsonic Transports," NASA CR-2467, September 1974. 


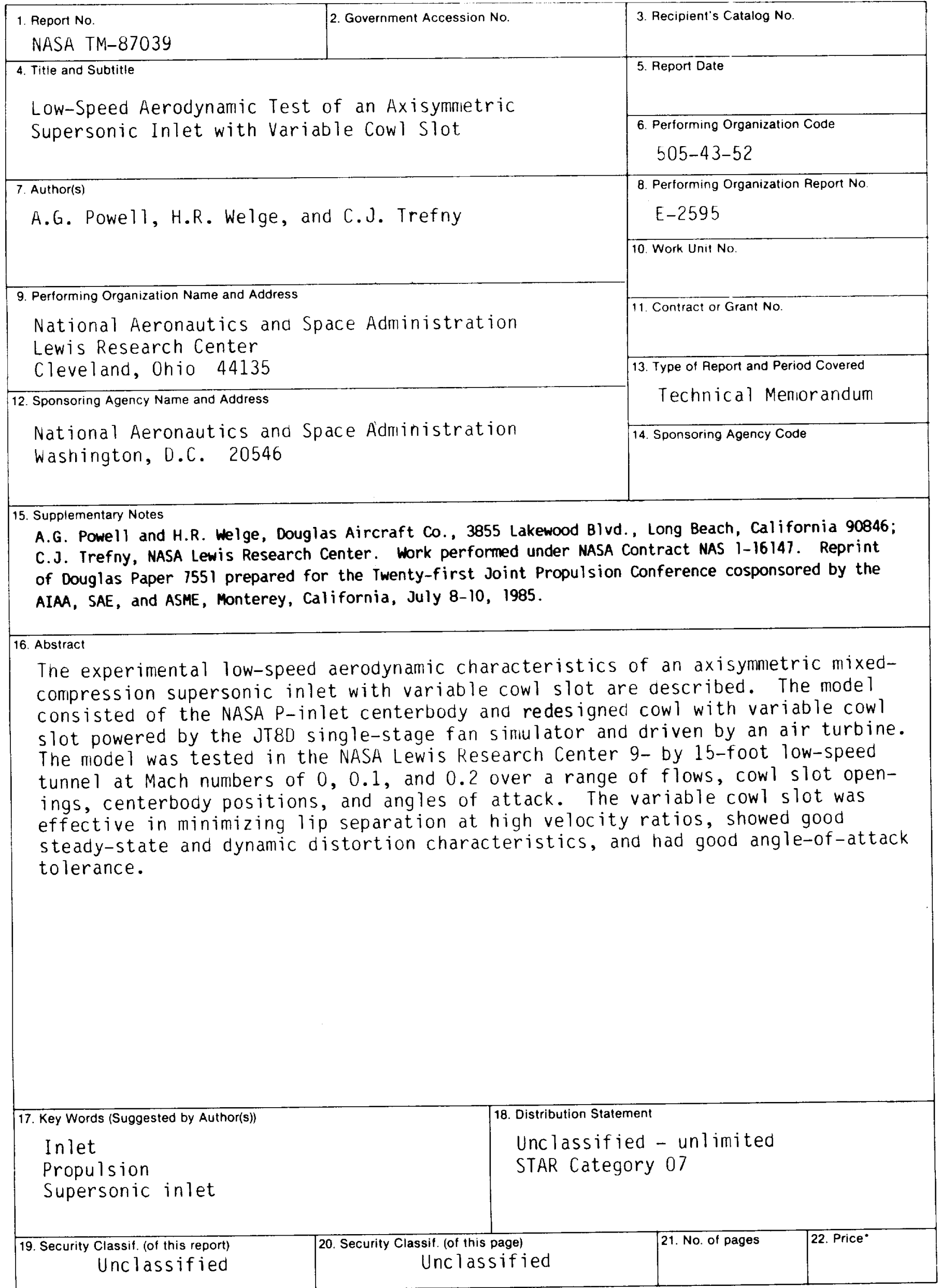

